\title{
The effects of auditory startle and nonstartle stimuli on step initiation in Parkinson's disease
}

\author{
Miguel Fernández-Del-Olmo, Olalla Bello, Virginia López-Alonso, José Andrés \\ Sánchez, Diego Santos-García, and Josep Valls-Solé
}

\begin{abstract}
Background. Auditory external cues enhance step initiation in Parkinson's disease (PD) patients. We wanted to explore whether a startle reaction has a comparable effect on step initiation in PD.

Methods. Thirteen PD patients and 13 aged-matched controls participated in this study. Electromyography pattern and onset toe-off time during a step initiation task were recorded in response to three different stimuli: a visual imperative stimulus; visual stimulus simultaneous with a nonstartle auditory stimulus and with a startle auditory stimulus.

Results. In all subjects, onset of tibialis anterior was faster in the startle auditory condition, compared with the nonstartle auditory condition. However, in the patient group, there was no difference in onset of soleus and toe-off between the startle and nonstartle conditions.

Conclusions. Startle reaction in PD patients demonstrates a disordered coupling between the anticipatory postural adjustments that initiate the weight shift and the movement to initiate toe-off during step initiation.
\end{abstract}

Key Words:

Parkinson; Gait initation; Step initiation; Startle

Step initiation is often impaired in Parkinson's disease (PD) as a result of abnormalities of the motor program responsible for the anticipatory postural adjustments (APAs).1 Recently, the startle reaction effect has been tested for step initiation, and results show that startle stimuli triggered APA in PD faster than during a nonstartle condition. 2 However, facilitation of gait initiation in PD patients occurs also with nonstartle external cues.3, 4 This facilitated reaction to a cue applied with another simultaneous stimulus is known as intersensory facilitation 5 and may explain effects observed with startle, in some experimental conditions. $6 \mathrm{We}$ undertook this study to investigate whether the latency shortening induced in step initiation by the simultaneous delivery of a startling stimulus has a similar degree and characteristics as the one induced by a nonstartling external cue in PD patients.

\section{Subjects and Methods}

Thirteen subjects diagnosed with PD (mean age: $56 \pm 13$ years; Table 1) and 13 age-matched healthy subjects (mean age: $53 \pm 11$ ) with no history of neurologic disease were included in this study. No subject showed dementia, as assessed by the Mini-Mental State Examination (MMSE). All tests were carried out while the patients were ON medication. The study was approved by the local ethics committee. All participants provided informed consent. 
Table 1. Details of PD patient characteristics

\begin{tabular}{|c|c|c|c|c|c|c|c|}
\hline $\begin{array}{l}\text { Patient } \\
\text { No. }\end{array}$ & $\begin{array}{c}\text { Age } \\
\text { (Years) }\end{array}$ & Sex & $\begin{array}{c}\text { Disease } \\
\text { Duration } \\
\text { (Years) }\end{array}$ & Type & $\mathrm{H} \& \mathrm{Y}$ & UPDRS Motor & Medication Per Day (mg) \\
\hline 1 & 67 & Male & 3 & M & 2 & 15 & $\begin{array}{l}\text { Levodopa/benserazide 500/125, rasagiline } 1 \text {, } \\
\text { pramipexole } 2.64\end{array}$ \\
\hline 2 & 37 & Male & 2 & M & 1 & 9 & Rasagiline 1 \\
\hline 3 & 66 & Female & 12 & $\mathrm{~T}$ & 2.5 & 12 & $\begin{array}{l}\text { Levodopa/carbidopa 200/50, levodopa/benserazide } \\
\text { 550/137.5, rotigotine 6, Rasagiline 1, amantadine } 200\end{array}$ \\
\hline 4 & 79 & Female & 7 & $\mathrm{AR}$ & 3 & 35 & Levodopa/carbidopa 400/50, pramipexole 0.18 \\
\hline 5 & 58 & Male & 6 & M & 2 & 23 & Levodopa/carbidopa 500/125, rasagiline 1 , rotigotine 4 \\
\hline 6 & 60 & Male & 6 & A & 2 & 12 & $\begin{array}{l}\text { Levodopa/carbidopa } 800 / 200 \text {, entacapone } 800 \text {, } \\
\text { pramipexole } 3.15\end{array}$ \\
\hline 7 & 60 & Male & 7 & M & 2 & 13 & $\begin{array}{l}\text { Levodopa/carbidopa 500/125, ropinirole } 12 \text {, } \\
\text { trihexyphenidyl } 2\end{array}$ \\
\hline 8 & 62 & Female & 2 & AR & 3 & 31 & $\begin{array}{l}\text { Levodopa/carbidopa } 600 / 150 \text {, entacapone } 600 \text {, rotigotine } \\
6 \text {, pramipexole } 3.15\end{array}$ \\
\hline 9 & 68 & Male & 1 & AR & 2.5 & 16 & $\begin{array}{l}\text { Levodopa/carbidopa 150/37.5, entacapone } 600 \text {, } \\
\text { rasagiline } 1\end{array}$ \\
\hline 10 & 50 & Male & 5 & $\mathrm{AR}$ & 2 & 19 & Levodopa/carbidopa 300/75, rasagiline 1 , rotigotine 8 \\
\hline 11 & 39 & Female & 1 & $\mathrm{~T}$ & 2 & 18 & $\begin{array}{l}\text { Levodopa/carbidopa 375/93.75, entacapone } 600 \text {, } \\
\text { rasagiline } 1\end{array}$ \\
\hline 12 & 45 & Male & 3 & $\mathrm{M}$ & 2 & 11 & $\begin{array}{l}\text { Levodopa/carbidopa } 225 / 56.25 \text {, entacapone } 600 \text {, } \\
\text { rasagiline } 1 \text {, rotigotine } 4\end{array}$ \\
\hline 13 & 40 & Female & 1 & M & 1 & 4 & Levodopa/carbidopa 300/75, rasagiline 1, rotigotine 6 \\
\hline Mean & 56 & & 4.3 & & 2 & 16.76 & \\
\hline SD & 13 & & 3.25 & & 0.63 & 8.6 & \\
\hline
\end{tabular}

Abbreviations: AR, akinetic-rigid; T, tremor-dominant; M, mixed; SD, standard deviation.

\section{Procedure}

Subjects were requested to maintain a stationary standing posture over two contact platforms (Bosco system). They were instructed to perform a rapid initiation of gait with their right leg in response to a visual imperative stimulus (IS) and keep walking until they completed three consecutive steps. The IS was a white $25-\mathrm{cm}^{2}$ square displayed on a black computer screen situated in front of the subject. A warning auditory cue preceded the IS with a variable period of 3 to 5 seconds. In some trials, the onset of the IS was simultaneous with an auditory stimulus, a 750-Hz tone burst lasting $30 \mathrm{~ms}$. The intensity of the auditory stimulus was set either low $(80 \mathrm{~dB}=\mathrm{LAS})$ or high enough to induce a startling reaction $(130 \mathrm{~dB}$ = SAS). The session consisted of one block of 25 trials: 15 trials consisted of only the IS (IS condition), five trials contained IS and LAS (LAS condition), and five trials contained IS and SAS (SAS condition). The order of the trials was randomized with a minimum intertrial interval of 10 seconds.

\section{Data Analysis}

Electromyographic (EMG) activity was recorded from the following muscles: tibialis anterior (TA); soleus (SOL); and rectus femoris (RF) of the right limb for the gait initiation session. EMG was recorded with pairs of surface silver/silver chloride electrodes $(0.7 \mathrm{~cm}$ in diameter). EMG from the right and left sternocleidomastoids (SCMs) was recorded during the practice trials to ensure that the startle reflex indeed occurred only when delivering a SAS. Raw EMG signals were amplified and filtered with a bandpass filter of $30 \mathrm{~Hz}$ to $1 \mathrm{kHz}$ (Digitimer Ltd., Welwyn Garden City, UK). Signals were digitized at $2 \mathrm{kHz}$ (CED Power1401; Cambridge Electronic Design, Cambridge, UK) and stored for off-line analysis.

Onset and offset latencies of EMG activity were visually determined using an interactive cursor of 1$\mathrm{ms}$ resolution in combination with a Teager-Kaiser energy operator (TKEO) method.7 Onset toe-off for step initiation was measured as the time between the imperative stimulus and toe-off in the right foot. 


\section{Statistical Analysis}

Repeated-measures analysis of variance (ANOVA) was performed with condition (IS, IS+LAS, and IS+SAS) and group (control and PD) for the following variables: onset latency and duration of SOL, TA, and RF EMG bursts and of soleus inhibition (SOLin). A post-hoc analysis (least significant difference) was carried out whenever differences were detected with ANOVA. Latency differences were calculated between TA and SOL (time TA-SOL). A $P$ value $\leq 0.05$ was considered statistically significant.

\section{Results}

In the PD group, SOL inhibition was excluded from the analysis because it was not measurable in 9 of 13 of the patients, in whom no consistent SOL tonic activity was observed during standing (Fig. 1).

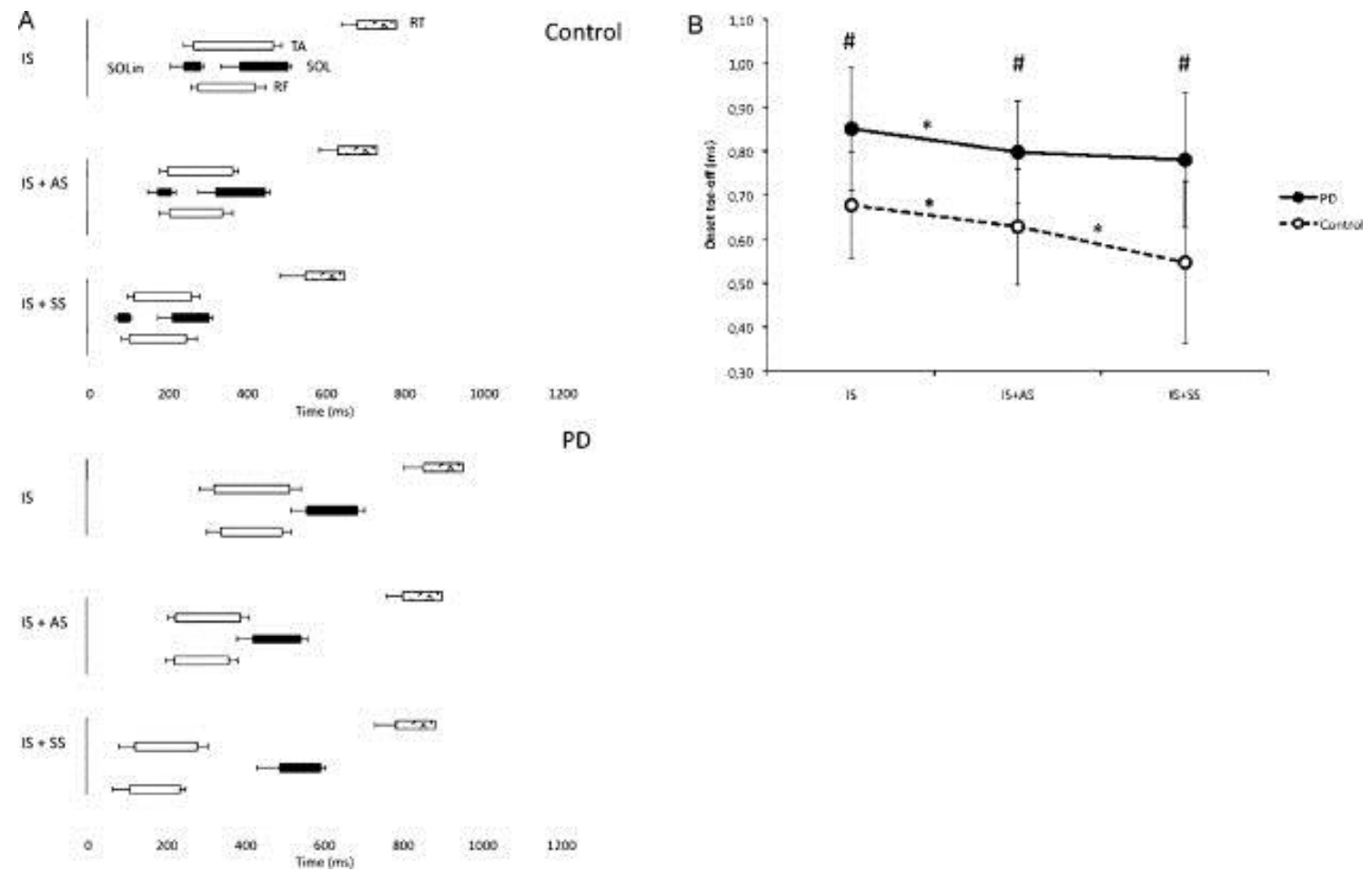

Figure 1. (A) Schematic representation of the mean EMG pattern in the gait initiation task in controls and PD patients across conditions. (IS) imperative visual stimulus; (IS+AS) visual plus auditory stimulus; (IS+SS) visual plus startle auditory stimulu; (RT) reaction time for toe-off; (SOLin) soleus inhibition; (SOL) soleus burst; (TA) tibialisis anterior burst; (RF) recto femoris burst. Except SOLin, the leftward extent of the bars represents the mean onset latency, whereas the horizontal line shows +1 EM. Length of the bars represents the duration of the EMG bursts, and the horizontal lines at the right side of the bar show +1 EM. Note: (1) the absence of SOLin in the PD group and (2) the significant delay between the onset TA and SOL for the IS+SS condition in PD groups, in comparison with the other conditions. (B) Reaction times for the step initiation task across conditions. *Significant differences between conditions $(P<0.05)$; " between groups $(P<0.05)$.

The ANOVA showed a main effect of condition on onset latency of TA $(P<0.0001)$ and RF $(P<$ 0.0001), with no significant group interactions or group effect (Table 2; Fig. 1A). For both muscles, onset latency was slower in the IS condition, compared with the LAS condition $(P=0.001$ and $P<0.0001$ for TA and RF, respectively) and SAS condition ( $P<0.0001$ for both muscles). In addition, onset latency for the SAS condition was significantly faster than for the LAS condition $(P=0.002$ and $P=0.001$ for TA and RF, respectively). The ANOVA for the onset latency of SOL showed significant effects of condition $(P=0.002)$, group $(P=0.003)$, and a condition*group interaction $(P=0.002)$. Both groups showed a significantly faster SOL onset latency in the LAS condition, in comparison with the IS condition $(P=$ 0.028 and $P=0.04$ for PD and control group, respectively). Although the SOL onset latency was significantly faster for the SAS condition than for the LAS and IS conditions in the control group $(P<$ 0.005 in both comparisons), differences were not significant for the PD group between SAS and IS 
conditions $(P=0.31)$ or between SAS and LAS conditions $(P=0.5)$. In addition, ANOVA showed a significant condition*group interaction for the TA-SOL time difference $(P=0.018)$ and a significant overall group effect $(P=0.004)$. Post-hoc analysis revealed that the TAL-SOL time difference in patients were significantly longer than in control subjects for all conditions $(P<0.04$ for IS and LAS; $P<0.01$ for SAS). In the PD group, the TA-SOL time difference was significantly longer in the SAS condition than in the IS condition $(P=0.048)$, whereas no significant differences were found between these conditions in the control group.

Table 2. Onset latency and duration of EMG bursts

\begin{tabular}{|c|c|c|c|c|c|c|}
\hline \multirow{2}{*}{$\begin{array}{l}\text { Condition } \\
\text { Parameters/Group }\end{array}$} & \multicolumn{2}{|c|}{ IS } & \multicolumn{2}{|c|}{ LAS } & \multicolumn{2}{|c|}{ SAS } \\
\hline & PD & Control & PD & Control & PD & Control \\
\hline \multicolumn{7}{|l|}{ Step initiation } \\
\hline Time to toe-off & $850 \pm 38$ & $677 \pm 33$ & $797 \pm 32$ & $628 \pm 36$ & $780 \pm 42$ & $546 \pm 51$ \\
\hline Onset TA & $318 \pm 105$ & $262 \pm 71$ & $220 \pm 51$ & $196 \pm 54$ & $118 \pm 42$ & $105 \pm 23$ \\
\hline Duration TA & $192 \pm 85$ & $203 \pm 61$ & $166 \pm 64$ & $167 \pm 37$ & $158 \pm 77$ & $145 \pm 64$ \\
\hline Onset SOLin & - & $238 \pm 96$ & - & $170 \pm 67$ & - & $71 \pm 19$ \\
\hline Duration SOLin & - & $43 \pm 20$ & - & $37 \pm 32$ & - & $29 \pm 8$ \\
\hline Onset SOL & $554 \pm 116$ & $380 \pm 136$ & $416 \pm 111$ & $319 \pm 127$ & $485 \pm 163$ & $208 \pm 102$ \\
\hline Duration SOL & $128 \pm 51$ & $122 \pm 25$ & $124 \pm 45$ & $124 \pm 42$ & $104 \pm 39$ & $94 \pm 26$ \\
\hline Time TA-SOL & $236 \pm 129$ & $153 \pm 106$ & $247 \pm 93$ & $130 \pm 94$ & $311 \pm 199$ & $112 \pm 82$ \\
\hline Onset RF & $336 \pm 102$ & $274 \pm 52$ & $218 \pm 62$ & $202 \pm 76$ & $105 \pm 45$ & $100 \pm 65$ \\
\hline Duration RF & $155 \pm 65$ & $144 \pm 76$ & $138 \pm 67$ & $134 \pm 73$ & $127 \pm 42$ & $120 \pm 53$ \\
\hline
\end{tabular}

The ANOVA for the onset of toe-off showed a significant main effect for condition $(P<0.0001)$ and a significant condition*group interaction $(P=0.035)$ (Fig. 1B). Onset of toe-off was significantly slower in PD patients than in controls ( $P<0.01$ for all comparisons). Both groups showed a significant, but mild, shortening of onset of toe-off in the LAS condition $(\sim 6 \%)$, in comparison with the IS condition $(P<$ $0.0001)$. In the SAS condition, only the control group demonstrated a further decrease in onset toe-off $(\sim 14 \%)$, in comparison with the LAS condition $(P<0.005)$. In PD patients, the onset toe-off was significantly faster in the SAS condition than in the IS condition $(P<0.005)$. However, unlike the controls, there were no significant differences in onset toe-off between SAS and LAS conditions.

\section{Discussion}

During the IS condition, EMG analysis of the step initiation showed a heterogeneous pattern across the PD patients. The timing between tibialis and soleus activation in patients was longer than in control subjects, suggesting an impaired coordination between the postural phase and step initiation. Similar findings have been reported in previous studies.1, 2, 8-10 These abnormalities in EMG pattern can explain the longer onset toe-off of the step initiation in patients, compared to the control group. Our findings are in contrast to those of other studies reporting improved gait initiation in PD on medication. 3 For instance, Burgleih-Jacobs et al.3 did not find differences in the push-off phase during a cued step task between PD on and control subjects. However, they showed that the push-off duration in the PD group (on or off) was still longer than controls. Rocchi et al.11 reported an improvement of APA between off and on condition, but this effect was affected by the initial stance position. In fact, with a wide stance, the patients in on had a significantly longer APA than control subjects. Thus, it seems that more variables than medication can affect gait initiation in PD patients.

When a nonstartling auditory stimulus was presented simultaneously with the IS, our PD patients were able to speed up the onset of both tibialis and soleus activations, in comparison with the single presentation of the IS. This observation has been reported on before.3, 4 The mechanism underlying this 
effect remains unclear, although nondopaminergic pathways, such as the cerebello-thalamocortical pathways, have been implicated.12

The tibialis and soleus onset activations were ealier for the startle, compared with a nonstartling, stimulus in the control group. However, this additional beneficial effect of the startling stimulus was only present for the tibialis, but not for the soleus, in the PD group. In line with a recent study with PD patients in off-medication state, 2 PD patients showed an earlier onset of the tibialis anterior muscle EMG activity in the startling, compared with the nonstartling, condition, suggesting that patients were able to prepare the anticipatory postural adjustments before an expected cue to initiate gait. However, our study suggests that this earlier tibialis activation did not translate into a faster toe-off. One possible explanation may be that the SOL activation at the end of the postural phase, which contributes to the lifting of the foot, was significantly delayed. This may be related to the impaired modulation of the soleus H-reflex that has been described in PD patients using auditory stimuli13 or transcranial magnetic stimulation.14 As a result of the long time period between the onset of tibialis activity and toe-off, we cannot exclude other afferent and efferent pathways that could explain this delay rather than the specific gait initiation pathway.

\section{Conclusions}

In summary, our results show that a startle stimulus during a gait initiation task leads to an earlier onset of tibialis anterior activity, although the timing of toe-off of the stepping leg was not significantly changed. This is of relevance, because it suggests that there is a disordered coupling between the APA that initiates the weight shift and the movement to initiate toe-off.

\section{Acknowledgements}

The authors are grateful to Noa Fogelson for the review of the manuscript for this article.

\section{References}

1 Crenna P, Frigo C, Giovannini P, Piccolo I. The initiation of gait in Parkinson's disease. In: Berardelli A, Benecke R, Manfredi M, Marsden CD, eds. Motor Disturbances II. San Diego, CA: Academic; 1990: 161-173.

2 Rogers M, Kennedy R, Palmer S, et al. Postural preparation prior to stepping in patients with Parkinson's disease. J Neurophysiol 2011; 106: 915-924.

3 Burleigh-Jacobs A, Horak FB, Nutt JG, Obeso JA. Step initiation in Parkinson's disease: influence of levodopa and external sensory triggers. Mov Disord 1997; 12: 206-215.

4 Dibble LE, Nicholson DE, Shultz B, MacWilliams BA, Marcus RL, Moncur C. Sensory cueing effects on maximal speed gait initiation in persons with Parkinson's disease and healthy elders. Gait Posture 2004; 19: 215-225.

5 Gielen SC, Schmidt RA, Van de Heuvel PJ. On the nature of intersensory facilitation of reaction time. Percept Psychophys 1983; 34: 161-168.

6 Queralt A, Weerdesteyn V, van Duijnhoven HJ, Castellote JM, Valls-Solé J, Duysens J. The effects of an auditory startle on obstacle avoidance during walking. J Physiol 2008; 586: 4453-4463.

7 Solnik S, Rider P, Steinweg K, DeVita P, Hortobágyi T. Teager-Kaiser energy operator signal conditioning improves EMG onset detection. Eur J Appl Physiol 2010; 110: 489-498.

8 Halliday SE, Winter DA, Frank JS, Patla AE, Prince F. The initiation of gait in young, elderly, and Parkinson's disease subjects. Gait Posture 1998; 8; 8-14.

9 Gantchev N, Viallet F, Aurenty R, Massion J. Forward versus backward oriented stepping movements in parkinsonian patients. Motor Control 2000; 4: 453-468.

10 Crenna P, Carpinella I, Rabuffetti M, Rizzone M, Lopiano L, Lanotte M, Ferrarin M. Impact of subthalamic nucleus stimulation on the initiation of gait in Parkinson's disease. Exp Brain Res 2006; 172: 519-532.

11 Rocchi L, Chiari L, Mancini M, Carlson-Kuhta P, Gross A, Horak FB. Step initiation in Parkinson's disease: influence of initial stance conditions. Neurosci Lett 2006; 406: 128-132.

12 Glickstein M, Stein J. Paradoxical movement in Parkinson's disease. Trends Neurosci 1991; 14: 480-482.

13 Delwaide PJ, Pepin JL, Maertens de Noordhout A. The audiospinal reaction in parkinsonian patients reflects functional changes in reticular nuclei. Ann Neurol 1993; 33: 63-69.

14 Valls-Solé J, Valldeoriola F. Neurophysiological correlate of clinical signs in Parkinson's disease. Clin Neurophysiol 2002; 113: 792-805. 